\title{
Direct $\mathrm{N}_{2} \mathrm{O}_{5}$ reactivity measurements at a polluted coastal site
}

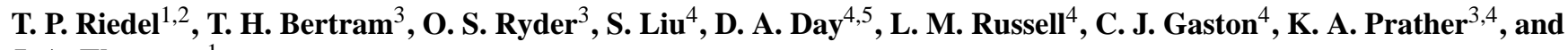 \\ J. A. Thornton ${ }^{1}$ \\ ${ }^{1}$ Department of Atmospheric Sciences, University of Washington, Seattle, USA \\ ${ }^{2}$ Department of Chemistry, University of Washington, Seattle, USA \\ ${ }^{3}$ Department of Chemistry and Biochemistry, University of California, San Diego, USA \\ ${ }^{4}$ Scripps Institution of Oceanography, San Diego, USA \\ ${ }^{5}$ Cooperative Institute for Research in the Environmental Sciences, University of Colorado, Boulder, USA
}

Correspondence to: J. A. Thornton (thornton@atmos.washington.edu)

Received: 15 November 2011 - Published in Atmos. Chem. Phys. Discuss.: 5 December 2011

Revised: 6 March 2012 - Accepted: 8 March 2012 - Published: 26 March 2012

\begin{abstract}
Direct measurements of $\mathrm{N}_{2} \mathrm{O}_{5}$ reactivity on ambient aerosol particles were made during September 2009 at the Scripps Institution of Oceanography (SIO) Pier facility located in La Jolla, CA. $\mathrm{N}_{2} \mathrm{O}_{5}$ reactivity measurements were made using a custom flow reactor and the particle modulation technique alongside measurements of aerosol particle size distributions and non-refractory composition. The pseudo-first order rate coefficients derived from the particle modulation technique and the particle surface area concentrations were used to determine the population average $\mathrm{N}_{2} \mathrm{O}_{5}$ reaction probability, $\gamma\left(\mathrm{N}_{2} \mathrm{O}_{5}\right)$, approximately every $50 \mathrm{~min}$. Insufficient environmental controls within the instrumentation trailer led us to restrict our analysis primarily to nighttime measurements. Within this subset of data, $\gamma\left(\mathrm{N}_{2} \mathrm{O}_{5}\right)$ ranged from $<0.001$ to 0.029 and showed significant dayto-day variations. We compare these data to a recent parameterization that utilizes aerosol composition measurements and an aerosol thermodynamics model. The parameterization captures several aspects of the measurements with similar general trends over the time series. However, the parameterization persistently overestimates the measurements by a factor of 1.5-3 and does not illustrate the same extent of variability. Assuming chloride is internally mixed across the particle population leads to the largest overestimates. Removing this assumption only partially reduces the discrepancies, suggesting that other particle characteristics that can suppress $\gamma\left(\mathrm{N}_{2} \mathrm{O}_{5}\right)$ are important, such as organic coatings or non-aqueous particles. The largest apparent driver of day-today variability in the measured $\gamma\left(\mathrm{N}_{2} \mathrm{O}_{5}\right)$ at this site was the particle nitrate loading, as inferred from both the measured particle composition and the parameterizations. The relative
\end{abstract}

change in measured $\gamma\left(\mathrm{N}_{2} \mathrm{O}_{5}\right)$ as a function of particle nitrate loading appears to be consistent with expectations based on laboratory data, providing direct support for the atmospheric importance of the so-called "nitrate effect".

\section{Introduction}

Nitrogen oxides $\left(\mathrm{NO}_{\mathrm{x}} \equiv \mathrm{NO}+\mathrm{NO}_{2}\right)$ influence air quality and climate by regulating tropospheric ozone $\left(\mathrm{O}_{3}\right)$ production and hydroxyl radical $(\mathrm{OH})$ abundances which in turn affect aerosol mass formation and the lifetime of the greenhouse gases such as methane (Jacob, 2000; Logan et al., 1981; Shindell et al., 2009). $\mathrm{NO}_{\mathrm{x}}$ is present largely through emissions from anthropogenic activities such as motor vehicle use, industrial processes, agriculture, and power generation. These emissions have steadily increased since preindustrial times and are expected to continue increasing globally (Ohara et al., 2007; Yienger, 1999).

Understanding $\mathrm{NO}_{\mathrm{x}}$ removal pathways is crucial to accurately assessing its impacts. In the troposphere, conversion of $\mathrm{NO}_{\mathrm{x}}$ to $\mathrm{HNO}_{3}$ is the dominant removal process due to the efficient wet and dry deposition of $\mathrm{HNO}_{3}$. During the daytime, $\mathrm{NO}_{\mathrm{x}}$ is converted to $\mathrm{HNO}_{3}$ by $\mathrm{OH}$. At night in the presence of ozone, $\mathrm{NO}_{\mathrm{x}}$ is converted into the nitrate radical, $\mathrm{NO}_{3}$, by reaction of $\mathrm{NO}_{2}$ with $\mathrm{O}_{3}$. The nitrate radical can react with a variety of different volatile organic compounds (VOC) or again with $\mathrm{NO}_{2}$ to form dinitrogen pentoxide, $\mathrm{N}_{2} \mathrm{O}_{5}$, which can react on aerosol particles. Nocturnal reactions of $\mathrm{NO}_{3}$ and $\mathrm{N}_{2} \mathrm{O}_{5}$ to terminal products such as alkyl nitrates and nitric acid are thought to account for 
$20-80 \%$ of $\mathrm{NO}_{\mathrm{x}}$ removal in polluted regions (Alexander et al., 2009; Brown et al., 2004; Dentener and Crutzen, 1993). These previous studies have assumed that $\mathrm{N}_{2} \mathrm{O}_{5}$ reactions on particles proceed solely via a hydrolysis channel to form two $\mathrm{HNO}_{3}$ molecules. Laboratory studies and recent field work has shown that $\mathrm{N}_{2} \mathrm{O}_{5}$ reactions on chloride containing aerosol particles can efficiently proceed through a second channel to form nitryl chloride, $\mathrm{ClNO}_{2}$, in both continental and marine locations (Behnke et al., 1997; Finlayson-Pitts et al., 1989; Osthoff et al., 2008; Roberts et al., 2009; Thornton et al., 2010). $\mathrm{ClNO}_{2}$ is a photolabile compound that releases atomic chlorine and $\mathrm{NO}_{\mathrm{x}}$ upon photolysis, its formation thereby decreases nocturnal $\mathrm{NO}_{\mathrm{x}}$ losses due to $\mathrm{HNO}_{3}$ formation while liberating a strong oxidant. The importance of this second channel has implications for both the reactive halogen budget and the efficiency of photochemical ozone production. Moreover, there remains significant uncertainty in the efficiency of $\mathrm{N}_{2} \mathrm{O}_{5}$ reactions on atmospheric particles.

The heterogeneous reaction rate of $\mathrm{N}_{2} \mathrm{O}_{5}$ on aerosol particles is calculated from the product of two quantities, the collision frequency between $\mathrm{N}_{2} \mathrm{O}_{5}$ molecules with particle surface area in a volume of air and the probability that $\mathrm{N}_{2} \mathrm{O}_{5}$ reacts given a collision, $\gamma\left(\mathrm{N}_{2} \mathrm{O}_{5}\right)$, also called the reactive uptake coefficient. This relationship is shown in Eq. (1) where $\omega$ is the average molecular speed of an $\mathrm{N}_{2} \mathrm{O}_{5}$ molecule $\left(\mathrm{m} \mathrm{s}^{-1}\right)$ and SA is the surface area concentration of aerosol particles $\left(\mathrm{m}^{2} \mathrm{~m}^{-3}\right)$.

$\frac{d\left[\mathrm{~N}_{2} \mathrm{O}_{5}\right]}{d t}=\frac{\gamma\left(\mathrm{N}_{2} \mathrm{O}_{5}\right)\left[\mathrm{N}_{2} \mathrm{O}_{5}\right] \mathrm{SA} \omega}{4}$

Eq. (1) neglects any limitations resulting from gas-phase diffusion to the particle surfaces which are likely negligible under our measurement conditions $\left(\gamma\left(\mathrm{N}_{2} \mathrm{O}_{5}\right)<0.05\right.$ and $\left.r_{p}<2 \mu \mathrm{m}\right) . \gamma\left(\mathrm{N}_{2} \mathrm{O}_{5}\right)$ represents the net result of multiphase chemistry that is a complex function of various particle properties including chemical composition, liquid water content, particle phase state (solid vs. liquid), mixing state, morphology of particle constituents across the size distribution, and $\mathrm{pH}$. Routine, quantitative measurements of the aforementioned particle properties in ambient air are rare at best, and the fundamental dependence of $\gamma\left(\mathrm{N}_{2} \mathrm{O}_{5}\right)$ on some of these properties, in particular organic composition and mixing state is lacking. Therefore, our understanding of the absolute and relative rates of $\mathrm{N}_{2} \mathrm{O}_{5}$ reaction channels in ambient particles remains poor. These issues also pose significant challenges for accurately incorporating these processes in atmospheric chemical models. Models must parameterize the reaction probability based on laboratory studies that use highly idealized particle compositions, and then also make assumptions about the mixing state of atmospheric particles.

Laboratory studies have shown that $\gamma\left(\mathrm{N}_{2} \mathrm{O}_{5}\right)$ can span several orders of magnitude depending upon particle composition and phase state (Hallquist et al., 2003; Hu and Abbatt, 1997; Kane et al., 2001; McNeill et al., 2006; Mozurkewich and Calvert, 1988; Robinson et al., 1997). Particulate water, chloride, nitrate, and organic particle coatings can all have effects on the $\mathrm{N}_{2} \mathrm{O}_{5}$ reaction probability (Bertram and Thornton, 2009; Bertram et al., 2009b; Cosman and Bertram, 2008; Folkers et al., 2003; Mentel et al., 1999; Park et al., 2007; Thornton et al., 2003; Thornton and Abbatt, 2005; Wahner et al., 1998). These findings have led to the development of a working mechanism, Reactions (R1)-(R4).

$$
\begin{aligned}
& \mathrm{N}_{2} \mathrm{O}_{5}(g) \leftrightarrow \mathrm{N}_{2} \mathrm{O}_{5}(\mathrm{aq}) \\
& \mathrm{N}_{2} \mathrm{O}_{5}(\mathrm{aq})+\mathrm{H}_{2} \mathrm{O}(\mathrm{l}) \rightarrow \mathrm{H}_{2} \mathrm{ONO}_{2}{ }^{+}(\mathrm{aq})+\mathrm{NO}_{3}{ }^{-}(\mathrm{aq}) \\
& \mathrm{H}_{2} \mathrm{ONO}_{2}{ }^{+}(\mathrm{aq})+\mathrm{NO}_{3}{ }^{-}(\mathrm{aq}) \rightarrow \mathrm{N}_{2} \mathrm{O}_{5}(\mathrm{aq})+\mathrm{H}_{2} \mathrm{O}(\mathrm{l}) \\
& \mathrm{H}_{2} \mathrm{ONO}_{2}{ }^{+}(\mathrm{aq})+\mathrm{H}_{2} \mathrm{O}(\mathrm{l}) \rightarrow \mathrm{H}_{3} \mathrm{O}^{+}(\mathrm{aq})+\mathrm{HNO}_{3}(\mathrm{aq}) \\
& \mathrm{H}_{2} \mathrm{ONO}_{2}{ }^{+}(\mathrm{aq})+\mathrm{Cl}^{-}(\mathrm{aq}) \rightarrow \mathrm{ClNO}_{2}(\mathrm{aq})+\mathrm{H}_{2} \mathrm{O}(\mathrm{l})
\end{aligned}
$$

Increases in particulate liquid water enhance $\gamma\left(\mathrm{N}_{2} \mathrm{O}_{5}\right)$, ultimately up to a value limited by Reaction (R1), by increasing the rates of solvation and hydrolysis reactions of accommodated $\mathrm{N}_{2} \mathrm{O}_{5}$ molecules (R2 and R3) (Bertram and Thornton, 2009; Thornton et al., 2003). The presence of particulate nitrate hinders $\mathrm{N}_{2} \mathrm{O}_{5}$ uptake, commonly called the "nitrate effect", presumably by forcing the solvated $\mathrm{N}_{2} \mathrm{O}_{5}$ intermediate back to reactants (R2b) (Wahner et al., 1998). The presence of particulate chloride provides an additional reaction channel for the solvated $\mathrm{N}_{2} \mathrm{O}_{5}$ intermediate (R4) (Behnke et al., 1997; Finlayson-Pitts et al., 1989; Roberts et al., 2009). This additional nucleophile can change the product distributions and increase the rate of $\mathrm{N}_{2} \mathrm{O}_{5}$ uptake in particles by overcoming the nitrate effect (Bertram and Thornton, 2009). That is, there is a connection, in terms of particle chloride content, between $\gamma\left(\mathrm{N}_{2} \mathrm{O}_{5}\right)$ and the branching ratio that predicts the $\mathrm{ClNO}_{2}$ produced per reaction of $\mathrm{N}_{2} \mathrm{O}_{5}$ on aerosol particles $(\phi)$.

$\phi\left(\mathrm{ClNO}_{2}\right)=\frac{\text { Rate }_{\mathrm{R} 4}}{\text { Rate }_{\mathrm{R} 3}+\text { Rate }_{\mathrm{R} 4}}$

The presence of organic compounds and their effect on the reaction probability remain a particular challenge to assess. Surface active organics and organic coatings generally appear to lower $\gamma\left(\mathrm{N}_{2} \mathrm{O}_{5}\right)$ (Cosman et al., 2008; Folkers et al., 2003; McNeill et al., 2006; Park et al., 2007; Thornton and Abbatt, 2005).

Parameterizations of $\gamma\left(\mathrm{N}_{2} \mathrm{O}_{5}\right)$ as a function of particle composition, based on the above laboratory findings, have only recently begun to be tested with field observations, a step that is ultimately necessary for accurate representation of nocturnal $\mathrm{NO}_{\mathrm{x}}$ processes in large-scale chemical transport models (Bertram and Thornton, 2009; Brown et al., 2009). Bertram et al. (2009b) using the same direct reactivity approach described here, illustrated that $\gamma\left(\mathrm{N}_{2} \mathrm{O}_{5}\right)$ depended strongly on particulate organic matter loading during a stagnation event in which SOA mass increased substantially relative to inorganic components. The $\gamma\left(\mathrm{N}_{2} \mathrm{O}_{5}\right)$ decreased with 
increasing particulate organic mass fraction, which would be inconsistent with a purely hygroscopic organic aerosol.

Brown et al. (2006) used observations of $\mathrm{NO}_{2}, \mathrm{O}_{3}, \mathrm{NO}_{3}$ and $\mathrm{N}_{2} \mathrm{O}_{5}$ to determine the steady state lifetime of $\mathrm{N}_{2} \mathrm{O}_{5}$ from which they estimated $\gamma\left(\mathrm{N}_{2} \mathrm{O}_{5}\right)$. In that study, and more recently, they demonstrated high spatial variability in $\gamma\left(\mathrm{N}_{2} \mathrm{O}_{5}\right)$, but a specific cause or causes in the variability were not clear from the available data (Brown et al., 2006, 2009).

We used the direct reactivity approach described in Bertram et al. (2009a) to make in situ measurements of the $\mathrm{N}_{2} \mathrm{O}_{5}$ reactivity on ambient aerosol particles over the course of two and a half weeks in a polluted coastal environment ( $\mathrm{La}$ Jolla, CA, USA). These data represent the first such measurements in a coastal region. This region routinely receives fresh and aged sea spray as well as particles associated with urban pollution, and therefore provides a broad range of particle types over which to study the response of $\gamma\left(\mathrm{N}_{2} \mathrm{O}_{5}\right)$. Using aerosol composition and meteorological measurements, we illustrate a strong influence of particulate nitrate on the observed $\gamma\left(\mathrm{N}_{2} \mathrm{O}_{5}\right)$ over the course of the study that is quantitatively consistent with that expected from laboratory studies. Other mechanisms of suppression are also apparent, but remain to be conclusively identified.

\section{Site description and methods}

Measurements of $\mathrm{N}_{2} \mathrm{O}_{5}$ reactivity and other variables were made continuously from 11-28 September 2009, at the Scripps Pier $\left(32.867^{\circ},-117.257^{\circ}\right)$ located on the Scripps Institution of Oceanography on the UC San Diego campus in La Jolla, CA. Supporting measurements included sizeresolved non-refractory aerosol composition from an Aerosol Mass Spectrometer (AMS), aerosol size distributions, $\mathrm{NO}_{\mathrm{x}}$, $\mathrm{O}_{3}$, and meteorological measurements such as temperature, relative humidity, pressure, wind speed and direction.

Ambient temperature $(T)$, relative humidity $(\mathrm{RH})$, and wind speed and direction measurements were obtained from an existing weather station operated by SIO (archived data can be found at http://meteora.ucsd.edu/wx_pages/scripps. html). RH governs particle water content as well as the reaction efficiency of $\mathrm{N}_{2} \mathrm{O}_{5}$ on the flow reactor walls and is thus an important variable both in ambient air and within the flow reactor. We determined the RH within the flow reactor from the ambient RH and $T$ by assuming constant water vapor mixing ratio between ambient air and the air sampled into the flow reactor. A high time resolution temperature measurement taken in the instrument trailer adjacent to the flow reactor apparatus was used with ambient $\mathrm{RH}$ and $\mathrm{T}$ to calculate a flow reactor RH. The ambient and flow reactor RH are shown in Fig. 1a for the entirety of the study. Characteristic of a coastal setting, ambient RH was typically about $70 \%$ with little diurnal cycle except for a few days during which continental flow dominated bringing low RH. Due to
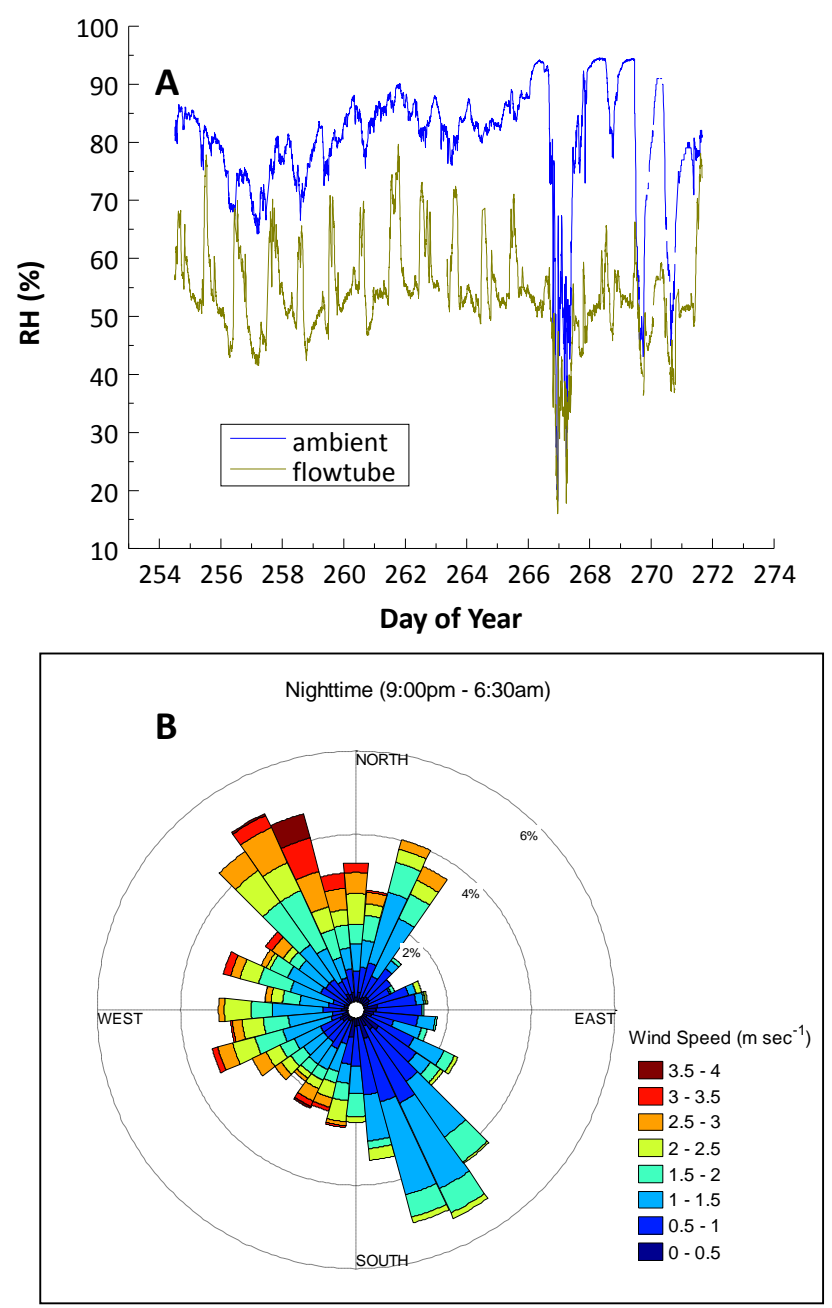

Fig. 1. Meteorological conditions during the measurement campaign. (A) The ambient relative humidity (RH\%) is shown in blue. The calculated flow reactor RH is shown in olive. The large swings in flowtube RH accompany rapid temperature swings in the instrument trailer during the daytime. (B) A wind rose illustrating the nighttime wind conditions at the measurement site.

persistently warmer conditions within the trailer compared to ambient air, RH within the flow reactor was consistently lower than that outside. This condition suggests a possible biasing of $\gamma\left(\mathrm{N}_{2} \mathrm{O}_{5}\right)$ low relative to its actual value in ambient air, though most recent laboratory studies illustrate only a weak $\gamma\left(\mathrm{N}_{2} \mathrm{O}_{5}\right)$ dependence on $\mathrm{RH}$ for aqueous solution particles at RH $>50 \%$ (Davis et al., 2008; Folkers et al., 2003; Thornton et al., 2003). As illustrated in Fig. 1b, a range of air mass source regions were sampled during the campaign. The wind rose represents only wind direction and speeds for the periods between 09:00 p.m.-06:30 a.m. local time, when the bulk of the $\mathrm{N}_{2} \mathrm{O}_{5}$ reactivity measurements were obtained, so it is a subsample of all conditions experienced during the campaign. Nonetheless, clean marine air, marine air mixed 
with coastal urban pollution, and continental air were sampled during the campaign providing a variety of particle types and histories which are described in detail elsewhere (Liu et al., 2011).

Number size distributions were measured from 0.01$0.6 \mu \mathrm{m}$ at ambient RH with a Scanning Mobility Particle Sizer (SMPS) (TSI Inc. 3010 CPC \& TSI Inc. 3081 DMA)

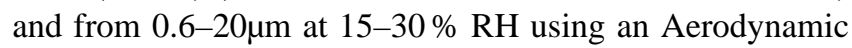
Particle Sizer (APS) (TSI Inc. 3321). Aerosols sampled into the SMPS were drawn through a short length of insulated tubing to maintain the RH at near ambient levels. These distributions were then converted to surface area concentrations (SA). The SMPS derived surface areas were not corrected for the lower RH in the flow reactor compared to ambient, and therefore represent an overestimate of the SA in this size range contributing to observed $\mathrm{N}_{2} \mathrm{O}_{5}$ reactivity. This overestimate would lead to $\gamma\left(\mathrm{N}_{2} \mathrm{O}_{5}\right)$ observations that are biased low depending on the actual hygroscopic growth factor of these particles. Assuming the particles are pure ammonium sulfate, our reported $\gamma\left(\mathrm{N}_{2} \mathrm{O}_{5}\right)$ values may be biased low by at most $50 \%$. The sampling configuration of the inlet and the reactivity apparatus (described below) was such that large particles were unlikely to efficiently transit to the flow reactor due to inertial impaction. Using the APS measured surface area distribution, scaled by a pure ammonium sulfate hygroscopic growth factor, we estimate that on average, approximately $60 \%$ of the supermicron surface area is lost in transit to the flow reactor (Baron and Willeke, 2001). Much of the supermicron surface area is lost when sampling at $2 \mathrm{slpm}$ through the 90 degree tee from the 14 slpm flow which results in a $\mathrm{d}_{50} \sim 2.5 \mu \mathrm{m}$. Moreover, during actual $\gamma\left(\mathrm{N}_{2} \mathrm{O}_{5}\right)$ measurements, the fraction of the scaled APS surface area estimated to reach the flow reactor was found to be on the order of $13 \%( \pm 10 \%)$ of the SMPS reported surface area. Therefore, we neglected it in the analyses performed here, leading to population average $\gamma\left(\mathrm{N}_{2} \mathrm{O}_{5}\right)$ that are possibly biased slightly high as a result. Neglecting this may also induce some variability in the agreement between observations and predictions due to a varying contribution of the supermicron particles to $\mathrm{N}_{2} \mathrm{O}_{5}$ reactivity. The focus here is on the submicron particle contribution to $\mathrm{N}_{2} \mathrm{O}_{5}$ reactivity.

Non-refractory size-resolved particle composition over the size range of $0.01-1 \mu \mathrm{m}$ was measured using an Aerodyne quadrupole aerosol mass spectrometer (AMS). The AMS cosampled from the same inlet as the $\mathrm{N}_{2} \mathrm{O}_{5}$ reactivity apparatus described below. Mass concentrations of organics, sulfate, ammonium, nitrate, and chloride were obtained at five minute time resolution. In addition, post-campaign positive matrix factorization (PMF) analysis separated the organic mass concentration into three factors: oxidized (aged combustion and biogenic SOA), biomass burning, and marine organic aerosol; OOA, BBOA, and MOA, respectively (Liu et al., 2011). These factors illustrate the variety of air masses sampled during the study period. Collectively we refer to the organic species as particulate organic mass (POM). These aerosol composition measurements and a recently developed $\mathrm{N}_{2} \mathrm{O}_{5}$ reaction probability parameterization were used to derive predictions of the $\mathrm{N}_{2} \mathrm{O}_{5}$ reaction probability for comparison with measurements. The parameterization estimates the reaction probability given the aerosol nitrate, chloride, and liquid water content (Bertram and Thornton, 2009). The latter were obtained using an online aerosol thermodynamic equilibrium model (AIM) (Wexler and Clegg, 2002) with the measured non-refractory ammonium, sulfate, nitrate, and chloride mass loadings, and flow reactor RH as inputs. Nonrefractory chloride does not include chloride from sea salt, which is not quantitatively measured by the AMS. Organic species were assumed to not contribute to the overall particle water content and were not included in the aerosol modeling. This assumption is appropriate if organics are indeed hydrophobic and do not inhibit water uptake. Over the course of this study, there was significant alkane character to the organic mass which would support the assumption that organic species were hydrophobic (Liu et al., 2011), but we do not have direct knowledge of the particle hygroscopicity. We also used the AMS size-resolved particle composition to calculate surface area weighted $\mathrm{N}_{2} \mathrm{O}_{5}$ reaction probabilities. The net result was not substantially different to the simpler approach using the bulk mass composition, which we report here.

$\mathrm{N}_{2} \mathrm{O}_{5}$ reactivity was measured using a similar version of the flow reactor apparatus described previously (Bertram et al 2009). Briefly, ambient air was sampled from $4 \mathrm{~m}$ above the pier (15 m a.s.l.) at 14 standard liters per minute (slpm) through a $6 \mathrm{~mm}$ inner diameter (ID) stainless steel tube. $2 \mathrm{slpm}$ was drawn through a $90^{\circ}$ tee from the main $14 \mathrm{slpm}$ flow and sent through a 1 meter long, $6 \mathrm{~mm}$ ID stainless steel tube to the flow reactor. Air then passed into a conical aluminum entrance to the flow reactor, either directly or first through a glass woven filter that removed $\sim 99 \%$ of the aerosol surface area. The reaction of excess $\mathrm{NO}_{2}$ with ozone, produced from the photolysis of $\mathrm{O}_{2}$ in high purity air, served as the $\mathrm{N}_{2} \mathrm{O}_{5}$ source. A 40 standard cubic centimeters per minute ( $\mathrm{sccm}$ ) flow of $\mathrm{N}_{2}$ containing the $\mathrm{N}_{2} \mathrm{O}_{5}$ from the relatively constant $( \pm 2 \%)$ source was then added to the ambient air stream. The main body of the flow reactor is a $15 \mathrm{~cm}$ inner diameter, $90 \mathrm{~cm}$ long stainless-steel tube which was coated with a halocarbon wax to suppress wall reactions. The dimensions and flow rate gave a residence time $\left(t_{\text {res }}\right)$ of $\sim 8 \mathrm{~min} . \mathrm{N}_{2} \mathrm{O}_{5}$ eluting from the flow reactor was monitored using an iodide ion $\left(\mathrm{I}^{-}\right)$chemical ionization mass spectrometer (CIMS) described previously (Kercher et al., 2009).

By monitoring the $\mathrm{N}_{2} \mathrm{O}_{5}$ source output with the CIMS and periodically filtering out aerosol particles, the $\mathrm{N}_{2} \mathrm{O}_{5}$-particle reaction probability was retrieved by the so-called particle modulation technique. A representative measurement cycle is shown in Fig. 2. Under an assumption of constant wall loss conditions between filter on/off states, the relative changes in the $\mathrm{N}_{2} \mathrm{O}_{5}$ signal (SIG) between the filter on/off states was used to extract the pseudo first order rate constant 
for $\mathrm{N}_{2} \mathrm{O}_{5}$-particle reactions ( $k_{\text {het }}$ ) about every 50 min. We allowed $15 \mathrm{~min}$ of equilibration time between filter states and then averaged the $\mathrm{N}_{2} \mathrm{O}_{5}$ signal for $10 \mathrm{~min}$. The resulting $k_{\text {het }}$ was then used along with the measured particle surface area concentration (SA) to calculate the reaction probability, as shown in Eqs. (3) and (4). The single-point precision for a reaction probability measurement at a particle surface area concentration of $100 \mu \mathrm{m}^{2} \mathrm{~cm}^{-3}$ is \pm 0.01 and decreases to \pm 0.003 with a surface area concentration of $300 \mu \mathrm{m}^{2} \mathrm{~cm}^{-3}$. This imprecision is driven primarily by random variations in source output and detector noise and thus adjacent measurements can be averaged to reduce the scatter. A more complete discussion of the reactivity apparatus and its capabilities can be found in other publications (Bertram et al., 2009a,b).

$k_{\mathrm{het}}=-\frac{\ln \left(\frac{\mathrm{SIG}^{w /}}{\mathrm{SIG}^{w / 0}}\right)}{t_{\mathrm{res}}}$

$\gamma\left(\mathrm{N}_{2} \mathrm{O}_{5}\right) \approx \frac{4 k_{\text {het }}}{\omega \mathrm{SA}}$

\subsection{Data quality and averaging}

The most significant challenge to obtaining meaningful reactivity measurements was maintaining a relatively constant temperature within the instrument trailer over the course of a filter on/off/on cycle. Large temperature swings affect the relative humidity, and fluctuations in RH change the wall loss rate within the flow reactor (Bertram et al., 2009a).

In light of these effects, we instituted a fairly rigorous data quality filter. We reject any reaction probabilities obtained when the RH in the flow reactor measured at the end of a filter on/off/on cycle was more than $2 \%$ different from that measured at the start. Large variations in flow reactor RH, inferred from trailer temperature swings, were most evident during the daytime hours as the instrument trailer heated up and personnel entered and exited the trailer. The nighttime temperatures were much more stable. Therefore $72 \%$ of the 106 reaction probabilities that passed the quality assurance checks occurred at night between 09:00 p.m. and 06:30 a.m. local time. During these time periods the winds (shown in Fig. 1b) came predominantly from the SSE, corresponding to urban San Diego and La Jolla, CA, and the NNW potentially bringing air from the Los Angles urban area. Additionally, we reject any data where NO concentrations exceeded 750 pptv to avoid artificial reactivity changes caused by the $\mathrm{NO}_{3} / \mathrm{N}_{2} \mathrm{O}_{5}$ equilibrium (Bertram et al., 2009b).

Reactivity measurements that passed the above criteria were then averaged into $24 \mathrm{~h}$ bins, primarily to reduce pointto-point variation in the data caused by measurement imprecision. For figures showing $\gamma\left(\mathrm{N}_{2} \mathrm{O}_{5}\right)$, we report the bin mean as points, the standard deviation $(1 \sigma)$ to illustrate pointto-point variability within the bin as vertical bars, and the measurement error obtained by error propagation using the

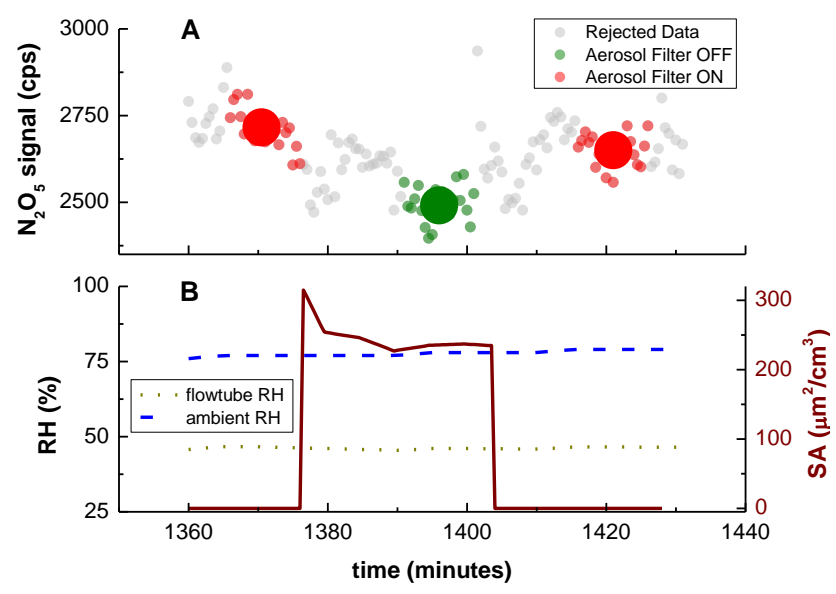

Fig. 2. (A) Select data illustrating the capabilities and precision of the reactivity apparatus over a single aerosol filter ON/OFF/ON cycle. Aerosol Filter ON indicates particles are not present in the flow reactor. Aerosol Filter OFF indicates when the reactor is sampling ambient particles. The size of the three large markers represents the $95 \%$ confidence range of signals incorporated in the average. (B) Ambient RH (blue dashed line), calculated flow reactor RH (olive dotted line), and particle surface area concentrations are shown for the same period. Surface area is only shown for the Filter OFF status and set to zero for the Filter ON status to illustrate the particle surface areas within the flow reactor.

SA precision dependence discussed above as gray shading. For comparison purposes, predictions of $\gamma\left(\mathrm{N}_{2} \mathrm{O}_{5}\right)$ from the parameterization were similarly averaged using only values generated from data obtained coincident with each individual reactivity measurement.

\section{Results and discussion}

The surface area concentration contributed by particles less than $0.6 \mu \mathrm{m}$ in diameter is shown in Fig. 3a, and the AMS reported non-refractory aerosol composition is shown in Fig. 3b. In general, over the course of the study, particle surface area correlated well with aerosol mass loadings. In terms of particle composition, two distinct periods are apparent over the study. The first period (days 254-260) was marked by high sulfate loadings with comparatively low POM and nitrate loadings. The bulk of the particle composition for this period is likely ammonium sulfate or ammonium bisulfate. Ammonium loadings largely followed sulfate trends. Ammonium sulfate aerosol is hygroscopic and an efficient substrate for $\mathrm{N}_{2} \mathrm{O}_{5}$-particle reactions, so $\gamma\left(\mathrm{N}_{2} \mathrm{O}_{5}\right)$ for this period are expected to be relatively high. The second period (days 261-272) has a notable drop in sulfate loadings and a substantial increase in particulate nitrate accompanied by an increase in POM. The largest nitrate loadings occurred when winds were out of the NNW, and the air may have originated from the Los Angeles area as noted above. Compared 

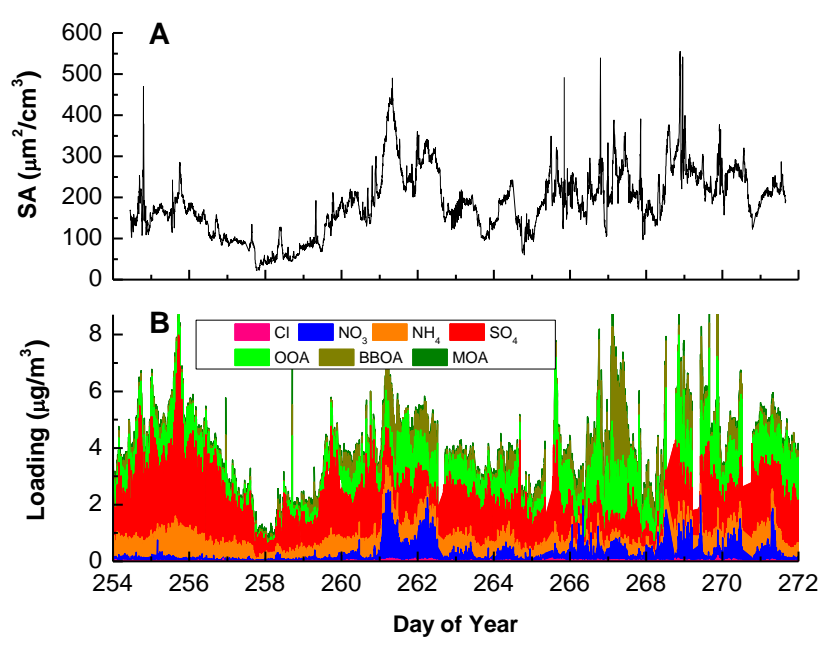

Fig. 3. (A) A full time series of measured particle surface area concentrations $(0.01-0.6 \mu \mathrm{m})$ at ambient RH conditions for the study period. (B) A full time series of AMS reported non-refractory particle composition for the study period with organics (shown in greens) differentiated by factor analysis as oxidized organic aerosol (OOA), biomass burning organic aerosol (BBOA), and marine organic aerosol (MOA). In general, high particle surface area correlated well with aerosol mass loadings indicating only a few periods in which submicron particle surface area were influenced by fresh sea salt emissions.

to the first period, $\gamma\left(\mathrm{N}_{2} \mathrm{O}_{5}\right)$ is expected to be relatively low in the second period due to an increase in the nitrate effect and the potential for non-hygroscopic organic species to lower, in a relative sense, the liquid water content or form coatings.

Sea salt chloride mass is not measured efficiently by the AMS, so the reported non-refractory chloride data represent a lower limit to actual particulate chloride loadings. Small chloride loadings relative to nitrate $\left(\mathrm{Cl}^{-}\right.$moles $/ \mathrm{NO}_{3}^{-}$moles $\sim 0.1$ ) have been shown to be able to negate the nitrate effect in laboratory studies (Bertram and Thornton, 2009). If the particles are internally mixed, then, in some instances during this study, the non-refractory chloride measured by the AMS, while a lower limit, is still large enough to overcome the nitrate effect and presumably drive $\gamma\left(\mathrm{N}_{2} \mathrm{O}_{5}\right)$ higher.

The mean of all $\gamma\left(\mathrm{N}_{2} \mathrm{O}_{5}\right)$ measured during the Pier study was 0.0054 with a standard deviation of 0.005 , and the measurements ranged from a minimum of $3 \times 10^{-5}$ to a maximum of 0.029 . We bin and average the 106 reaction probabilities into daily (24-h) bins requiring at least 3 reaction probability measurements per bin. The time series is shown in Fig. $4 \mathrm{a}$ as black squares. The vertical lines indicate the $1 \sigma$ variation of points within the bin. The gray shading represents the instrumental error obtained by propagating the SAdependent precision (see above) through the averaging.
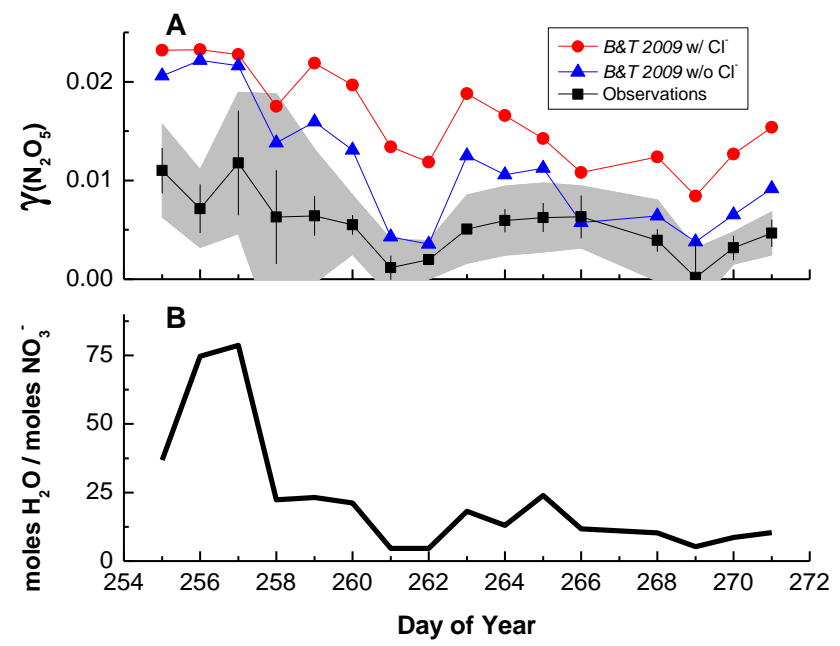

Fig. 4. (A) Observed (black squares) and parameterized (blue triangles and red circles) $\mathrm{N}_{2} \mathrm{O}_{5}$ reaction probabilities, $\gamma\left(\mathrm{N}_{2} \mathrm{O}_{5}\right)$, binned to a 24-hour time base for the entire study. The gray shaded area represents the estimated instrumental error, and the vertical bars represent the standard deviation $(1 \sigma)$ of the points in each bin. The red circles show the predictions of the full parameterization while the blue triangles show the predictions from the parameterization neglecting the chloride dependence. (B) 24-h bins of the mole ratio of particulate water predicted by the AIM model and the AMS reported nitrate loadings.

As seen in Fig. 4a, $\gamma\left(\mathrm{N}_{2} \mathrm{O}_{5}\right)$ during the early portion of the study (days 254-260) was relatively high, indicating efficient hydrolysis of $\mathrm{N}_{2} \mathrm{O}_{5}$ consistent with the high sulfate mass loadings relative to nitrate loadings. The mean $\gamma\left(\mathrm{N}_{2} \mathrm{O}_{5}\right)$ for this first period was 0.008 . This period also included the campaign maximum $\gamma\left(\mathrm{N}_{2} \mathrm{O}_{5}\right)$ of 0.029 . After day 260, the increase in the nitrate mass fraction coincides with a drop in $\gamma\left(\mathrm{N}_{2} \mathrm{O}_{5}\right)$ to a mean of 0.004 for this period. Figure $4 \mathrm{~b}$ shows the mole ratio of particulate water to particulate nitrate. Particulate water estimates are predicted from the thermodynamic aerosol equilibrium model. The two have competing effects on $\gamma\left(\mathrm{N}_{2} \mathrm{O}_{5}\right)$ as described above, and these effects are most apparent in the binned $\gamma\left(\mathrm{N}_{2} \mathrm{O}_{5}\right)$ values when the nitrate loadings increase after day 260. During the early portion the mole ratio is biased toward $\mathrm{H}_{2} \mathrm{O}$ with values near 75 , but as the study progresses the ratio changes toward nitrate with mean values near 12 , and $\gamma\left(\mathrm{N}_{2} \mathrm{O}_{5}\right)$ drops accordingly. The nitrate effect is most obvious in the period between days 260 and 262 where the binned $\gamma\left(\mathrm{N}_{2} \mathrm{O}_{5}\right)$ drops from 0.005 to 0.001 as the water to nitrate mole ratio drops from 20 to 6. Starting at day 262, the rise in the water to nitrate ratio coincides with increases in $\gamma\left(\mathrm{N}_{2} \mathrm{O}_{5}\right)$. Additionally, on day 269 the water to nitrate ratio shows a campaign minimum which also aligns with the minimum in $\gamma\left(\mathrm{N}_{2} \mathrm{O}_{5}\right)$.

Daily parameterized reaction probabilities are also calculated using the Bertram and Thornton (2009) parameterization with reported aerosol mass loadings and estimated 
particulate water from the AIM thermodynamic equilibrium model. The AIM model has been shown in other publications to reasonably estimate the particulate water content based on the inorganic particle composition (Engelhart et al., 2011). These predictions are shown with the 24-h binned $\gamma\left(\mathrm{N}_{2} \mathrm{O}_{5}\right)$ values in Fig. 4a. Predictions from the parameterizations were averaged using only output from the time periods for which a valid $\gamma\left(\mathrm{N}_{2} \mathrm{O}_{5}\right)$ measurement existed. The full reaction probability parameterization includes a chloride dependence, and predictions from this full parameterization are shown as red circles. The full parameterization estimates are consistently higher than the observed $\gamma\left(\mathrm{N}_{2} \mathrm{O}_{5}\right)$. Given the uncertainty in how chloride mass is distributed throughout the particle surface area distribution based on the AMS measurement, we also test the other extreme by neglecting the presence of particulate chloride in the parameterization. The estimates from the parameterization with chloride set equal to zero are also shown in Fig. 4a as blue squares. Even when neglecting aerosol chloride, the parameterized reaction probabilities remain on average 1.5 to 3 times larger than the observed. This result indicates either that there are deficiencies in the parameterizations when applied to ambient aerosols, such as a neglected form of $\mathrm{N}_{2} \mathrm{O}_{5}$ reactivity suppression, or alternatively, that there is a systematic bias in the field measurements. That said, both parameterized reaction probabilities broadly correlate with observed $\mathrm{N}_{2} \mathrm{O}_{5}$ reaction probabilities on average, showing maximum values in the early part of the study and depressions between day 260-262 and on day 269. Indeed, the parameterizations even show similar day-to-day variations, except the variations are much less pronounced in the parameterizations than in the observations.

The overestimates of the parameterizations are especially large during the first period of the study when particulate nitrate loadings are low. As noted above, some of the overestimation of the full parameterization may be caused by the assumption that chloride is internally mixed across all particles. The parameterization also has no explicit dependences on POM, the effects of which represent an area requiring more research. Similarly we neglect particle phase transitions and assume all particles are metastable solutions. Thus, if effloresced aerosol components were present in the atmosphere, then the parameterization would likely overestimate $\gamma\left(\mathrm{N}_{2} \mathrm{O}_{5}\right)$ given its strong dependence on particle phase (Thornton et al., 2003). Despite these deficiencies, the parameterization still manages to capture much of the dayto-day variability in $\gamma\left(\mathrm{N}_{2} \mathrm{O}_{5}\right)$. Moreover, the exclusion of particulate chloride from the parameterization doesn't vastly change the day-to-day behavior in the predictions relative to the observations. This result implies that nitrate concentrations relative to water must explain a significant amount of this variation in the parameterizations, and presumably that in the observations as well. In Fig. 5 we illustrate the extent to which the nitrate effect can explain the observed variations in $\gamma\left(\mathrm{N}_{2} \mathrm{O}_{5}\right)$ by binning the $24 \mathrm{~h}$ reaction probabilities (measured and parameterized) as a function of the
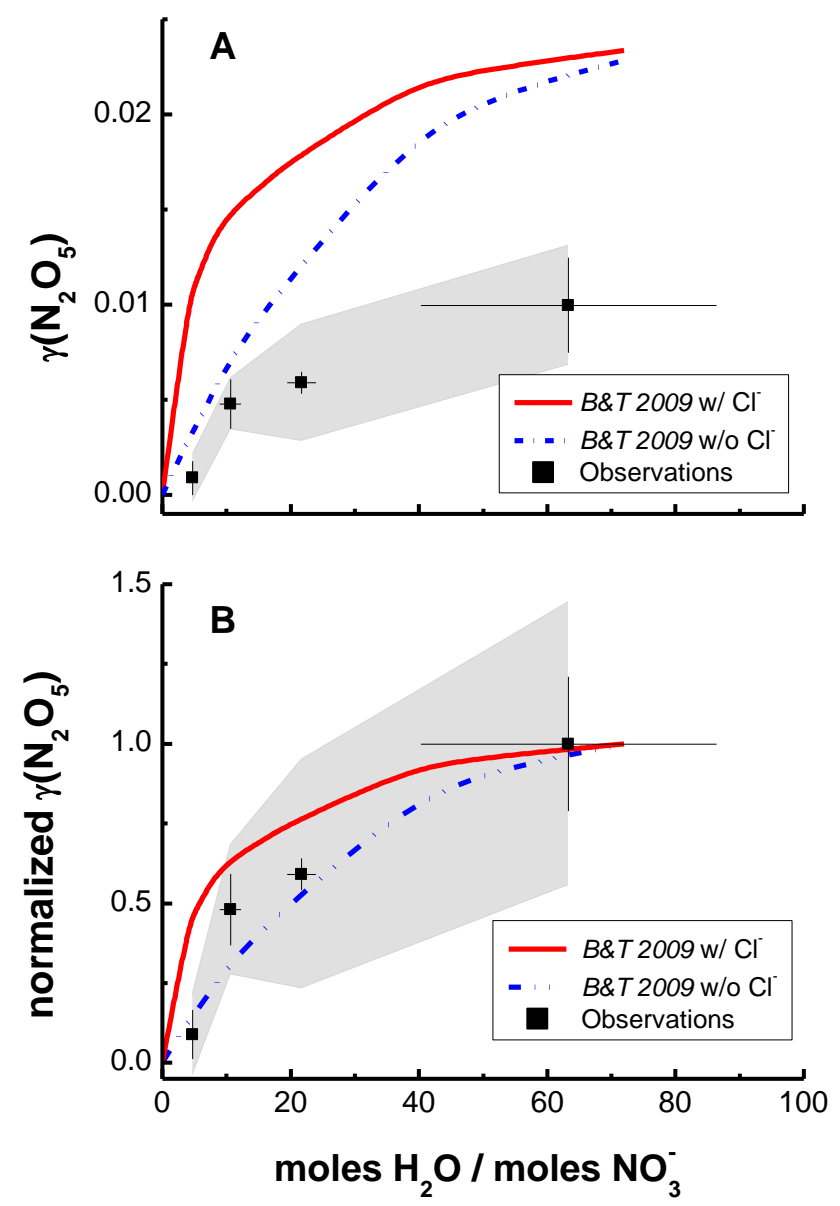

Fig. 5. (A) The observed dependence of $\mathrm{N}_{2} \mathrm{O}_{5}$ reaction probabilities (black squares) on the water to nitrate mole ratio (i.e. "the nitrate effect"). Parameterized reaction probabilities are also included for comparison. (B) Observed (black squares) and parameterized reaction probabilities normalized to maximum values. For both panels, the shaded area represents estimated error from the precision of the measurement technique. The bars represent the $1 \sigma$ variation of 24-h averaged points in each bin.

corresponding particulate water to nitrate ratios. We chose the water to nitrate bin widths such that the bins covered an appropriately large span of mole ratios over which the nitrate effect is apparent. Each bin has a minimum of three 24-h average points (corresponding to at least 9 raw observations). Figure 5a shows that the parameterization estimates follow the overall shape in the observed $\gamma\left(\mathrm{N}_{2} \mathrm{O}_{5}\right)$ relative to the water to nitrate mole ratio. However, in an absolute sense, the persistent overestimate of the observed data is also clear. When the observations and predictions are normalized to their respective maximum values in Fig. 5b, the agreement between the binned observations and the parameterization becomes most apparent. Here the observations follow quite well the functional dependence on the water to nitrate mole ratio as predicted by the parameterization. The Scripps 
Pier observations therefore suggest that the magnitude of the nitrate effect found in laboratory studies and recent parameterizations (e.g. Wahner et al., 1998; Bertram and Thornton, 2009) is consistent with that found in the atmosphere at least for the range of conditions sampled.

Using in situ measurements made in Seattle, WA, Bertram et al. (2009b) found $\gamma\left(\mathrm{N}_{2} \mathrm{O}_{5}\right)$ was suppressed with increasing POM to sulfate mass ratios. The $\mathrm{POM} / \mathrm{SO}_{4}$ ratios in that study spanned a range of approximately $2-12$. In contrast, over the course of the Scripps Pier study, $90 \%$ of the $\mathrm{POM} / \mathrm{SO}_{4}$ ratios were below 2. The Seattle observations showed an appreciable suppression of $\gamma\left(\mathrm{N}_{2} \mathrm{O}_{5}\right)$ at $\mathrm{POM} / \mathrm{SO}_{4}$ ratios above 6 , whereas our observations exhibit similar $\gamma\left(\mathrm{N}_{2} \mathrm{O}_{5}\right)$ values but at the significantly lower $\mathrm{POM} / \mathrm{SO}_{4} \mathrm{ra}-$ tios. Bertram et al. (2009b) argued that the decreasing trend in $\gamma\left(\mathrm{N}_{2} \mathrm{O}_{5}\right)$ with increasing $\mathrm{POM} / \mathrm{SO}_{4}$ in Seattle could be partly explained by a correlated increase in the nitrate effect if the increasing POM did not significantly contribute to liquid water content. Indeed, such a correlated impact between POM and nitrate appears in the Scripps Pier dataset as well. However, the differences in $\mathrm{POM} / \mathrm{SO}_{4}$ between these two locations indicate that either the organic components in the particles sampled at the Scripps Pier were substantially more effective at lowering $\gamma\left(\mathrm{N}_{2} \mathrm{O}_{5}\right)$ per contribution to particle mass than those in Seattle, or still another driver of $\gamma\left(\mathrm{N}_{2} \mathrm{O}_{5}\right)$ variability is operating at the Scripps Pier location. The explicit role of organics species on $\gamma\left(\mathrm{N}_{2} \mathrm{O}_{5}\right)$ remains to be determined and should be a topic of future investigations.

Additionally we estimated the $\mathrm{ClNO}_{2}$ branching ratio $\left(\phi\left(\mathrm{ClNO}_{2}\right)\right.$ - also referred to as the yield) using the reactivity apparatus. Uncalibrated $\mathrm{ClNO}_{2}$ signals were monitored by the CIMS during the $\mathrm{N}_{2} \mathrm{O}_{5}$ uptake experiments. Despite the uncertainties resulting from the uncalibrated signals, $\phi\left(\mathrm{ClNO}_{2}\right)$ values obtained are consistent with the low $\gamma\left(\mathrm{N}_{2} \mathrm{O}_{5}\right)$ values. The mean $\phi\left(\mathrm{ClNO}_{2}\right)$ was $\sim 10 \%$ with a standard deviation of $\sim 10 \%$. It should be stated that under atmospheric conditions it is likely that significant $\mathrm{ClNO}_{2}$ formation occurs on supermicron particle surface area, the majority of which is likely lost in transit to the flow reactor as we describe above. Therefore these yield estimates are likely lower limits. With this in mind, the $\mathrm{ClNO}_{2}$ yields show no appreciable trend with AMS measured chloride, $\mathrm{H}_{2} \mathrm{O} / \mathrm{NO}_{3}$, or $\mathrm{POM} / \mathrm{SO}_{4}$. Experiments of this type certainly warrant additional investigations.

\section{Conclusions and atmospheric implications}

We report direct in situ measurements of the $\mathrm{N}_{2} \mathrm{O}_{5}$-aerosol reaction probability taken in the late summer in La Jolla, CA, using a recently developed heterogeneous reactivity apparatus. Particulate nitrate appears to have the most important day-to-day influence on the measured reaction probabilities during the study. The suppression effect of nitrate can be clearly seen in daily averages, and the observed dependence on the water to nitrate ratio within ambient particles closely resembles the expected relationship based on previous laboratory studies. Given the prevalence of particulate nitrate in polluted urban areas, especially during winter when $\mathrm{N}_{2} \mathrm{O}_{5}$ chemistry is likely to be most important, chemical transport models should incorporate the nitrate effect into $\mathrm{N}_{2} \mathrm{O}_{5}$ reaction probabilities used therein. Our results suggest the existing parameterizations adequately capture the nitrate effect for the conditions sampled at the Scripps Pier. While the nitrate effect is likely a significant contributor to the variations in the Scripps Pier $\gamma\left(\mathrm{N}_{2} \mathrm{O}_{5}\right)$ measurements, the data also illustrate that an unidentified, yet persistent, means of suppression exists in addition to the nitrate effect, perhaps connected to POM but the mechanism remains unclear.

Though chloride is expected to be an important driver of the $\mathrm{N}_{2} \mathrm{O}_{5}$ reaction probability, it does not appear to play a large role in the reaction probabilities reported here. This conclusion is based on the fact that predictions which include the expected chloride effect in a bulk sense have worse agreement with observations compared to those which assume particulate chloride is negligible in the particles that dominate the surface area of the submicron mode. This finding has important implications not only for accurately predicting $\gamma\left(\mathrm{N}_{2} \mathrm{O}_{5}\right)$ in models, but also for determining the efficiency of halogen activation by $\mathrm{N}_{2} \mathrm{O}_{5}$. Assuming chloride was internally mixed across the submicron particle size distribution, and importantly, in particles containing nitrate, led to a large overestimate of $\gamma\left(\mathrm{N}_{2} \mathrm{O}_{5}\right)$ compared to observations. Given the connection between the $\gamma\left(\mathrm{N}_{2} \mathrm{O}_{5}\right)$ and the branching ratio to $\mathrm{ClNO}_{2}$ production (see Eq. 2), these results imply that $\mathrm{ClNO}_{2}$ production in this coastal environment may not be $100 \%$ efficient. Thus, to further our understanding of $\mathrm{ClNO}_{2}$ production efficiencies, closure experiments that utilize simultaneous quantitative measurements of size-resolved inorganic particle composition and $\gamma\left(\mathrm{N}_{2} \mathrm{O}_{5}\right)$ alongside a suite of important nighttime constituents will be necessary.

Acknowledgements. This work was supported by a grant from the National Science Foundation (NSF CAREER ATM-0846183 to J.A.T). T. P. R. is grateful for an Earth System Science graduate fellowship from the National Aeronautics and Space Administration (NASA NESSF NNX-10AN48H). The authors also thank Scripps Institution of Oceanography and UC San Diego for the use of their facilities.

Edited by: R. Harley

\section{References}

Alexander, B., Hastings, M. G., Allman, D. J., Dachs, J., Thornton, J. A., and Kunasek, S. A.: Quantifying atmospheric nitrate formation pathways based on a global model of the oxygen isotopic composition $\left(\Delta^{17} \mathrm{O}\right)$ of atmospheric nitrate, Atmos. Chem. Phys., 9, 5043-5056, doi:10.5194/acp-9-5043-2009, 2009. 
Baron, P. A. and Willeke, K.: Aerosol Measurement: Principles, Techniques, and Applications, 2 edn., Wiley-Interscience, New York, USA, 2001.

Behnke, W., George, C., Scheer, V., and Zetzsch, C.: Production and decay of $\mathrm{ClNO}_{2}$, from the reaction of gaseous $\mathrm{N}_{2} \mathrm{O}_{5}$ with $\mathrm{NaCl}$ solution: Bulk and aerosol experiments, J. Geophys. Res.Atmos., 102, 3795-3804, doi:10.1029/96jd03057, 1997.

Bertram, T. H. and Thornton, J. A.: Toward a general parameterization of $\mathrm{N}_{2} \mathrm{O}_{5}$ reactivity on aqueous particles: the competing effects of particle liquid water, nitrate and chloride, Atmos. Chem. Phys., 9, 8351-8363, doi:10.5194/acp-9-8351-2009, 2009.

Bertram, T. H., Thornton, J. A., and Riedel, T. P.: An experimental technique for the direct measurement of $\mathrm{N}_{2} \mathrm{O}_{5}$ reactivity on ambient particles, Atmos. Meas. Tech., 2, 231-242, doi:10.5194/amt-2-231-2009, 2009a.

Bertram, T. H., Thornton, J. A., Riedel, T. P., Middlebrook, A. M., Bahreini, R., Bates, T. S., Quinn, P. K., and Coffman, D. J.: Direct observations of $\mathrm{N}_{2} \mathrm{O}_{5}$ reactivity on ambient aerosol particles, Geophys. Res. Lett., 36, L19803, doi:10.1029/2009g1040248, 2009b.

Brown, S. S., Dibb, J. E., Stark, H., Aldener, M., Vozella, M., Whitlow, S., Williams, E. J., Lerner, B. M., Jakoubek, R., Middlebrook, A. M., DeGouw, J. A., Warneke, C., Goldan, P. D., Kuster, W. C., Angevine, W. M., Sueper, D. T., Quinn, P. K., Bates, T. S., Meagher, J. F., Fehsenfeld, F. C., and Ravishankara, A. R.: Nighttime removal of $\mathrm{NO}_{\mathrm{x}}$ in the summer marine boundary layer, Geophys. Res. Lett., 31, L07108, doi:10.1029/2004gl019412, 2004.

Brown, S. S., Ryerson, T. B., Wollny, A. G., Brock, C. A., Peltier, R., Sullivan, A. P., Weber, R. J., Dube, W. P., Trainer, M., Meagher, J. F., Fehsenfeld, F. C., and Ravishankara, A. R.: Variability in nocturnal nitrogen oxide processing and its role in regional air quality, Science, 311, 67-70, doi:10.1126/science.1120120, 2006.

Brown, S. S., Dube, W. P., Fuchs, H., Ryerson, T. B., Wollny, A. G., Brock, C. A., Bahreini, R., Middlebrook, A. M., Neuman, J. A., Atlas, E., Roberts, J. M., Osthoff, H. D., Trainer, M., Fehsenfeld, F. C., and Ravishankara, A. R.: Reactive uptake coefficients for $\mathrm{N}_{2} \mathrm{O}_{5}$ determined from aircraft measurements during the Second Texas Air Quality Study: Comparison to current model parameterizations, J. Geophys. Res.-Atmos., 114, D00F10, doi:10.1029/2008jd011679, 2009.

Cosman, L. M. and Bertram, A. K.: Reactive uptake of $\mathrm{N}_{2} \mathrm{O}_{5}$ on aqueous $\mathrm{H}_{2} \mathrm{SO}_{4}$ solutions coated with 1-component and 2component monolayers, J. Phys. Chem. A, 112, 4625-4635, doi:10.1021/jp8005469, 2008.

Cosman, L. M., Knopf, D. A., and Bertram, A. K.: $\mathrm{N}_{2} \mathrm{O}_{5}$ reactive uptake on aqueous sulfuric acid solutions coated with branched and straight-chain insoluble organic surfactants, J. Phys. Chem. A, 112, 2386-2396, doi:10.1021/jp710685r, 2008.

Davis, J. M., Bhave, P. V., and Foley, K. M.: Parameterization of $\mathrm{N}_{2} \mathrm{O}_{5}$ reaction probabilities on the surface of particles containing ammonium, sulfate, and nitrate, Atmos. Chem. Phys., 8, 52955311, doi:10.5194/acp-8-5295-2008, 2008.

Dentener, F. J. and Crutzen, P. J.: Reaction of $\mathrm{N}_{2} \mathrm{O}_{5}$ on tropospheric aerosols - Impacts on the global distributions of $\mathrm{NO}_{\mathrm{x}}, \mathrm{O}_{3}$, AND OH, J. Geophys. Res.-Atmos., 98, 7149-7163, doi:10.1029/92jd02979, 1993.

Engelhart, G. J., Hildebrandt, L., Kostenidou, E., Mihalopoulos,
N., Donahue, N. M., and Pandis, S. N.: Water content of aged aerosol, Atmos. Chem. Phys., 11, 911-920, doi:10.5194/acp-11911-2011, 2011.

Finlayson-Pitts, B. J., Ezell, M. J., and Pitts, J. N.: Formation of chemically active chlorine compounds by reactions of atmospheric $\mathrm{NaCl}$ particles with gaseous $\mathrm{N}_{2} \mathrm{O}_{5}$ and $\mathrm{ClONO}_{2}$, Nature, 337, 241-244, doi:10.1038/337241a0, 1989.

Folkers, M., Mentel, T. F., and Wahner, A.: Influence of an organic coating on the reactivity of aqueous aerosols probed by the heterogeneous hydrolysis of $\mathrm{N}_{2} \mathrm{O}_{5}$, Geophys. Res. Lett., 30, 1644, doi:10.1029/2003g1017168, 2003.

Hallquist, M., Stewart, D. J., Stephenson, S. K., and Cox, R. A.: Hydrolysis of $\mathrm{N}_{2} \mathrm{O}_{5}$ on sub-micron sulfate aerosols, Phys. Chem. Chem. Phys., 5, 3453-3463, doi:10.1039/b301827j, 2003.

$\mathrm{Hu}$, J. H. and Abbatt, J. P. D.: Reaction probabilities for $\mathrm{N}_{2} \mathrm{O}_{5}$ hydrolysis on sulfuric acid and ammonium sulfate aerosols at room temperature, J. Phys. Chem. A, 101, 871-878, doi:10.1021/jp9627436, 1997.

Jacob, D. J.: Heterogeneous chemistry and tropospheric ozone, Atmos. Environ., 34, 2131-2159, doi:10.1016/s13522310(99)00462-8, 2000.

Kane, S. M., Caloz, F., and Leu, M. T.: Heterogeneous uptake of gaseous $\mathrm{N}_{2} \mathrm{O}_{5}$ by $\left(\mathrm{NH}_{4}\right)_{2} \mathrm{SO}_{4}, \mathrm{NH}_{4} \mathrm{HSO}_{4}$, and $\mathrm{H}_{2} \mathrm{SO}_{4}$ aerosols, J. Phys. Chem. A, 105, 6465-6470, doi:10.1021/jp010490x, 2001.

Kercher, J. P., Riedel, T. P., and Thornton, J. A.: Chlorine activation by $\mathrm{N}_{2} \mathrm{O}_{5}$ : simultaneous, in situ detection of $\mathrm{ClNO}_{2}$ and $\mathrm{N}_{2} \mathrm{O}_{5}$ by chemical ionization mass spectrometry, Atmos. Meas. Tech., 2, 193-204, doi:10.5194/amt-2-193-2009, 2009.

Liu, S., Day, D. A., Shields, J. E., and Russell, L. M.: Ozonedriven photochemical formation of carboxylic acid groups from alkane groups, Atmos. Chem. Phys. Discuss., 11, 7189-7233, doi:10.5194/acpd-11-7189-2011, 2011.

Logan, J. A., Prather, M. J., Wofsy, S. C., and McElroy, M. B.: Tropospheric Chemistry - a global perspective, J. Geophys. Res.-Oc. Atmos., 86, 7210-7254, doi:10.1029/JC086iC08p07210, 1981.

McNeill, V. F., Patterson, J., Wolfe, G. M., and Thornton, J. A.: The effect of varying levels of surfactant on the reactive uptake of $\mathrm{N}_{2} \mathrm{O}_{5}$ to aqueous aerosol, Atmos. Chem. Phys., 6, 1635-1644, doi:10.5194/acp-6-1635-2006, 2006.

Mentel, T. F., Sohn, M., and Wahner, A.: Nitrate effect in the heterogeneous hydrolysis of dinitrogen pentoxide on aqueous aerosols, Phys. Chem. Chem. Phys., 1, 5451-5457, doi:10.1039/a905338g, 1999.

Mozurkewich, M. and Calvert, J. G.: Reaction probability of $\mathrm{N}_{2} \mathrm{O}_{5}$ on aqueous aerosols, J. Geophys. Res.-Atmos., 93, 1588915896, doi:10.1029/JD093iD12p15889, 1988.

Ohara, T., Akimoto, H., Kurokawa, J., Horii, N., Yamaji, K., Yan, X., and Hayasaka, T.: An Asian emission inventory of anthropogenic emission sources for the period 19802020, Atmos. Chem. Phys., 7, 4419-4444, doi:10.5194/acp-7-4419-2007, 2007.

Osthoff, H. D., Roberts, J. M., Ravishankara, A. R., Williams, E. J., Lerner, B. M., Sommariva, R., Bates, T. S., Coffman, D., Quinn, P. K., Dibb, J. E., Stark, H., Burkholder, J. B., Talukdar, R. K., Meagher, J., Fehsenfeld, F. C., and Brown, S. S.: High levels of nitryl chloride in the polluted subtropical marine boundary layer, Nat. Geosci., 1, 324-328, doi:10.1038/ngeo177, 2008.

Park, S.-C., Burden, D. K., and Nathanson, G. M.: The inhibition 
of $\mathrm{N}_{2} \mathrm{O}_{5}$ hydrolysis in sulfuric acid by 1-butanol and 1hexanol surfactant coatings, J. Phys. Chem. A, 111, 2921-2929, doi:10.1021/jp068228h, 2007.

Roberts, J. M., Osthoff, H. D., Brown, S. S., Ravishankara, A. R., Coffman, D., Quinn, P., and Bates, T.: Laboratory studies of products of $\mathrm{N}_{2} \mathrm{O}_{5}$ uptake on $\mathrm{Cl}^{-}$containing substrates, Geophys. Res. Lett., 36, L20808, doi:10.1029/2009g1040448, 2009.

Robinson, G. N., Worsnop, D. R., Jayne, J. T., Kolb, C. E., and Davidovits, P.: Heterogeneous uptake of $\mathrm{ClONO}_{2}$ and $\mathrm{N}_{2} \mathrm{O}_{5}$ by sulfuric acid solutions, J. Geophys. Res.-Atmos., 102, 35833601, doi:10.1029/96jd03457, 1997.

Shindell, D. T., Faluvegi, G., Koch, D. M., Schmidt, G. A., Unger, N., and Bauer, S. E.: Improved Attribution of Climate Forcing to Emissions, Science, 326, 716-718, doi:10.1126/science.1174760, 2009.

Thornton, J. A. and Abbatt, J. P. D.: $\mathrm{N}_{2} \mathrm{O}_{5}$ reaction on submicron sea salt aerosol: Kinetics, products, and the effect of surface active organics, J. Phys. Chem. A, 109, 10004-10012, doi:10.1021/jp054183t, 2005.

Thornton, J. A., Braban, C. F., and Abbatt, J. P. D.: $\mathrm{N}_{2} \mathrm{O}_{5}$ hydrolysis on sub-micron organic aerosols: the effect of relative humidity, particle phase, and particle size, Phys. Chem. Chem. Phys., 5, 4593-4603, doi:10.1039/b307498f, 2003.
Thornton, J. A., Kercher, J. P., Riedel, T. P., Wagner, N. L., Cozic, J., Holloway, J. S., Dube, W. P., Wolfe, G. M., Quinn, P. K., Middlebrook, A. M., Alexander, B., and Brown, S. S.: A large atomic chlorine source inferred from mid-continental reactive nitrogen chemistry, Nature, 464, 271-274, doi:10.1038/nature08905, 2010.

Wahner, A., Mentel, T. F., Sohn, M., and Stier, J.: Heterogeneous reaction of $\mathrm{N}_{2} \mathrm{O}_{5}$ on sodium nitrate aerosol, J. Geophys. Res.Atmos., 103, 31103-31112, doi:10.1029/1998jd100022, 1998.

Wexler, A. S. and Clegg, S. L.: Atmospheric aerosol models for systems including the ions $\mathrm{H}^{+}, \mathrm{NH}_{4}^{+}, \mathrm{Na}^{+}, \mathrm{SO}_{4}^{2-}$, $\mathrm{NO}_{3}^{-}, \mathrm{Cl}^{-}, \mathrm{Br}^{-}$, and $\mathrm{H}_{2} \mathrm{O}$, J. Geophys. Res.-Atmos., 107, 4207, doi:10.1029/2001jd000451, 2002.

Yienger, J. J.: An evaluation of chemistry's role in the winterspring ozone maximum found in the northern midlatitude free troposphere, J. Geophys. Res.-Atmos., 104, 8329-8329, doi:10.1029/1999jd900140, 1999. 